\title{
Research on Performance of Pavement Cement Concrete Mixed with Iron Tailings and Fibers
}

\author{
Aiping Fei ${ }^{1,}$, Tiezhi Zhang ${ }^{1, b}$ \\ ${ }^{1}$ University of Science and Technology Liaoning, Qianshan Road No.185, Anshan 114051, China \\ afeiaipingxfr@126.com, bztz93j@163.com
}

Keywords: iron tailings, pavement cement concrete, numerical simulation, recycled material, concrete fiber

Abstract: In order to recycle iron tailings and fibers and analyze the performance of pavement cement concrete mixed with it, tests and numerical simulations are carried out. The compressive strength of concrete is significantly influenced by the content of Anshan iron tailings, and the highest 28-day compressive strength is $49.60 \mathrm{MPa}$ with $25 \%$ iron tailings in sand. The flexural strength of concrete with iron tailings meets the specifications for pavement with $25-30 \%$ iron tailings in sand. Iron tailings with a particle diameter in the range of $0.15-0.3 \mathrm{~mm}$ are more advantageous. In general, basalt fiber play a greater role than polypropylene fiber in the flexural strength of concrete in this paper.Numerical simulations accurately reflect the performance trends of the tests.

\section{Introduction}

Currently, there is a large amount of mining waste from mines, such as iron tailings. The maintenance costs and potential hazards of iron tailings are great because the amount of tailings is gradually increasing. Therefore, studies on the recovery and reuse of iron tailings have been carried out in a variety of industries ${ }^{[1,2]}$. The supply of natural sand, which is one of the components of pavement cement concrete, is insufficient. Moreover, the demand for cement concrete has greatly increased; thus, a substitute for this fine aggregate is needed. With a relatively stable composition and a suitable fineness index, also with fibers, iron tailings are suitable instead of natural sand in pavement cement concrete ${ }^{[3]}$. Therefore, tests of the compressive strength and flexural strength are carried out in this study to analyze the performance of pavement cement concrete mixed with iron tailings and fibers. In addition, numerical simulations are also performed. In order to analyze the influence on pavement cement concrete mixed with iron tailings and fibers, the mixing proportion and particle size of iron tailings are considered.

\section{Study of The mixing ratio}

\section{Raw materials}

The iron tailings in these tests are obtained from the Anshan area, which is a mineral-rich region. The physical and chemical compositions are listed in Table 1. Other materials are cement (32.5 MPa), water, gravels ranging from 5-20 $\mathrm{mm}$ in size, and a portion of natural sand.

Table 1. Chemical compositions of the iron tailings

\begin{tabular}{|c|c|c|c|c|}
\hline \multirow{2}{*}{ Tailings type } & \multicolumn{4}{|c|}{ Chemical compositions $(\%)$} \\
\hline & $\mathrm{SiO}_{2}$ & $\mathrm{Al}_{2} \mathrm{O}_{3}$ & $\mathrm{Fe}_{2} \mathrm{O}_{3}$ & $\mathrm{TiO}_{2}$ \\
\hline \multirow{5}{*}{ Iron tailings (Anshan) } & 73.3 & 4.07 & 11.6 & 0.16 \\
\hline & MgO & $\mathrm{CaO}$ & $\mathrm{Na}_{2} \mathrm{O}$ & $\mathbf{K}_{2} \mathbf{O}$ \\
\hline & 4.22 & 3.04 & 0.41 & 0.95 \\
\hline & $\mathrm{SO}_{3}$ & $\mathbf{P}_{2} \mathrm{O}_{5}$ & MnO & Burning iron \\
\hline & 0.25 & 0.19 & 0.14 & 2.18 \\
\hline
\end{tabular}




\section{Test procedure ${ }^{[4,5]}$}

The standard test procedures define the initial, reference, designed, and construction mixing ratios. Various aggregates and iron tailings are screened on a standard sieve with screening intervals of $0.15-0.3 \mathrm{~mm}$ and $0.3-0.6 \mathrm{~mm}$. Mixtures consisting of cement, water, sand, iron tailings, and gravels are stirred with a concrete mixer for $15 \mathrm{~s}$ and then formed into cubes with dimensions of $10 \times 10 \times 10 \mathrm{~cm}^{3}$. Three specimens are fabricated for each mixing ratio. The curing durations are 3, 7 , 18, and 28 days. Tests of the compressive strength and flexural strength are performed to analyze the influence of the iron tailings and fibers on the performance of pavement cement concrete.

1 . The cement concrete is a heterogeneous material composed of hardened cement, aggregates, pores, admixture, and so on. The designed mixing ratio must be strictly in accordance with published specifications ${ }^{[4,5,6]}$. Blending ratios of the iron tailings of $10 \%, 20 \%, 25 \%, 35 \%, 50 \%$, and $60 \%$ are used instead of sand. Other blending compounds include cement, water, sand, and additives.

2 . The effects of different particle sizes of iron tailings on pavement cement concrete are different. Thus, two particle-size ranges of $0.15-0.3 \mathrm{~mm}$ and $0.3-0.6 \mathrm{~mm}$ are tested. Data related to the control parameters of the mixing ratio are listed in Tables $2-4$.

3 .In order to enhancing the bending capacity of cement concrete with iron tailings, the fiber is added. There are two kinds of fibers, the one is basalt fiber, and another one is polypropylene fiber.

Table 3. The mix ratio of specimen with iron tailings of size range from $0.3-0.6 \mathrm{~mm}$

\begin{tabular}{|c|c|c|c|c|c|c|c|}
\hline \multicolumn{2}{|c|}{ Control parameters } & \multicolumn{6}{|c|}{$\begin{array}{c}\text { The specimen with iron tailings of } \\
\text { size range from } 0.15-0.3 \mathrm{~mm}\end{array}$} \\
\hline \multicolumn{2}{|c|}{$\mathrm{W} / \mathrm{C}$} & \multicolumn{6}{|c|}{0.4} \\
\hline \multicolumn{2}{|c|}{$\begin{array}{l}\text { Sand replacement ratio } \\
\qquad(\%)\end{array}$} & 10 & 20 & 25 & 35 & 50 & 60 \\
\hline \multicolumn{2}{|c|}{ Sand ration $(\%)$} & $\begin{array}{l}27 . \\
9\end{array}$ & $\begin{array}{l}25 . \\
6\end{array}$ & $\begin{array}{l}24 . \\
4\end{array}$ & $\begin{array}{l}21 . \\
8\end{array}$ & $\begin{array}{l}17 . \\
7\end{array}$ & $\begin{array}{l}9 . \\
7\end{array}$ \\
\hline \multicolumn{2}{|c|}{ Slump (mm) } & 40 & 35 & 35 & 32 & 30 & 27 \\
\hline \multirow{5}{*}{$\begin{array}{c}\text { Material } \\
\text { compositon } \\
(\mathrm{kg})\end{array}$} & $\begin{array}{l}\text { Rion } \\
\text { Tailings }\end{array}$ & $\begin{array}{l}0.5 \\
2\end{array}$ & $\begin{array}{l}1.0 \\
5\end{array}$ & $\begin{array}{l}1.3 \\
1\end{array}$ & $\begin{array}{l}1.8 \\
3\end{array}$ & $\begin{array}{l}2.6 \\
2\end{array}$ & $\begin{array}{l}3 . \\
14\end{array}$ \\
\hline & Sand & $\begin{array}{l}4, . \\
71 \\
\end{array}$ & $\begin{array}{c}4.1 \\
8\end{array}$ & $\begin{array}{c}3.9 \\
2\end{array}$ & 3.4 & $\begin{array}{c}2.6 \\
2 \\
\end{array}$ & $\begin{array}{c}2 . \\
1\end{array}$ \\
\hline & Cement & \multicolumn{6}{|c|}{5.12} \\
\hline & Water & \multicolumn{6}{|c|}{2.05} \\
\hline & Gravel & \multicolumn{6}{|c|}{12.16} \\
\hline \multicolumn{2}{|c|}{ Fiber } & \multicolumn{6}{|c|}{0.9} \\
\hline
\end{tabular}

Table 2.The mix ratio of standard test pieces

\begin{tabular}{|c|c|c|}
\hline \multicolumn{2}{|c|}{ Control parameters } & $\begin{array}{c}\text { The standard test } \\
\text { pieces }\end{array}$ \\
\hline \multicolumn{2}{|c|}{ W/C } & 0.4 \\
\hline \multirow{2}{*}{$\begin{array}{c}\text { Material } \\
\text { compositon } \\
\text { (kg) }\end{array}$} & Rion Tailings & 0 \\
\cline { 2 - 3 } & Water & 2.05 \\
\cline { 2 - 3 } & Cement & 5.12 \\
\cline { 2 - 3 } & Sand & 5.22 \\
\hline \multicolumn{2}{|c|}{ Sand ration(\%) } & 12.16 \\
\hline \multicolumn{2}{|c|}{ Sanel } & 30 \\
\hline \multicolumn{2}{|c|}{ Slump (mm) } & 35 \\
\hline
\end{tabular}

Table 4. The mix ratio of specimen with iron tailings of size range from $0.15-0.3 \mathrm{~mm}$

\begin{tabular}{|c|c|c|c|c|c|c|c|}
\hline \multicolumn{2}{|c|}{ Control parameters } & \multicolumn{6}{|c|}{$\begin{array}{c}\text { The specimen with iron tailings of } \\
\text { size range from } 0.3-0.6 \mathrm{~mm}\end{array}$} \\
\hline \multicolumn{2}{|c|}{$\mathrm{W} / \mathrm{C}$} & \multicolumn{6}{|c|}{0.4} \\
\hline \multicolumn{2}{|c|}{$\begin{array}{l}\text { Sand replacement ratio } \\
(\%)\end{array}$} & 10 & 20 & 25 & 35 & 50 & 60 \\
\hline \multicolumn{2}{|c|}{ Sand ration $(\%)$} & $\begin{array}{l}27 . \\
9\end{array}$ & $\begin{array}{l}25 . \\
6\end{array}$ & $\begin{array}{l}24 . \\
4\end{array}$ & $\begin{array}{l}21 . \\
8\end{array}$ & $\begin{array}{l}17 . \\
7\end{array}$ & 9.7 \\
\hline \multicolumn{2}{|c|}{ Slump (mm) } & 25 & 30 & 30 & 30 & 30 & 32 \\
\hline \multirow{5}{*}{$\begin{array}{c}\text { Material } \\
\text { compositon } \\
(\mathrm{kg})\end{array}$} & $\begin{array}{c}\text { Rion } \\
\text { Tailings }\end{array}$ & $\begin{array}{l}0.5 \\
2\end{array}$ & $\begin{array}{l}1.0 \\
5\end{array}$ & $\begin{array}{l}1.3 \\
1\end{array}$ & $\begin{array}{l}1.8 \\
3\end{array}$ & $\begin{array}{l}2.6 \\
2\end{array}$ & $\begin{array}{l}3.1 \\
4\end{array}$ \\
\hline & Sand & $\begin{array}{l}4, . \\
71\end{array}$ & $\begin{array}{c}4.1 \\
8\end{array}$ & $\begin{array}{c}3.9 \\
2\end{array}$ & 3.4 & $\begin{array}{c}2.6 \\
2\end{array}$ & 2.1 \\
\hline & Cement & \multicolumn{6}{|c|}{5.12} \\
\hline & Water & \multicolumn{6}{|c|}{2.05} \\
\hline & Gravel & \multicolumn{6}{|c|}{12.16} \\
\hline \multicolumn{2}{|c|}{ Fiber } & \multicolumn{6}{|c|}{0.9} \\
\hline
\end{tabular}




\section{Slump detection}

In order to assess the workability, slump detection must be carried out. A small amount of slurry is deposited from a slump cylinder when it is lifted. There are three specimens with the same mixing ratio; thus, the test data for each specimen are the average values of the three specimens. From Figure 1, it is found that the slump value is basically very stable as the content of iron tailings changes. There is no significant effect on pavement cement concrete with iron tailings.

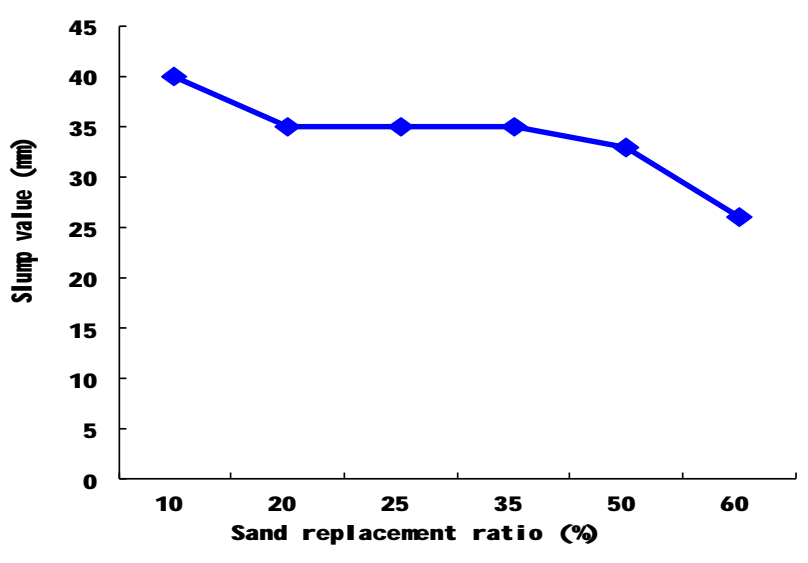

Figure 1. The slump curve of concrete with iron tailings and fibers

\section{Mechanical test analysis of pavement cement concrete with iron tailings and fibers}

For pavement cement concrete, the most important performance factors are the compressive and flexural strengths ${ }^{[8,9]}$. In order to study the influence of different contents and particle sizes of iron tailings and fibers on the mechanical properties of concrete, mass ratios of iron tailings of $10 \%, 20 \%, 25 \%, 35 \%, 50 \%$, and $60 \%$ - denoted with A, B, C, D, E, and F, respectively - in the particle-size range of $0.15-0.3 \mathrm{~mm}$ are used instead of sand. Similarly, mass ratios of iron tailings of $10 \%, 20 \%, 25 \%$, $35 \%, 50 \%$ and $60 \%$ - denoted with A', B', C', D', $\mathrm{E}^{\prime}$, and $\mathrm{F}^{\prime}$ in the particle-size range of $0.3-0.6 \mathrm{~mm}$ are also used. Normal concrete is indicated with an "N". The two different kinds of fibers show in

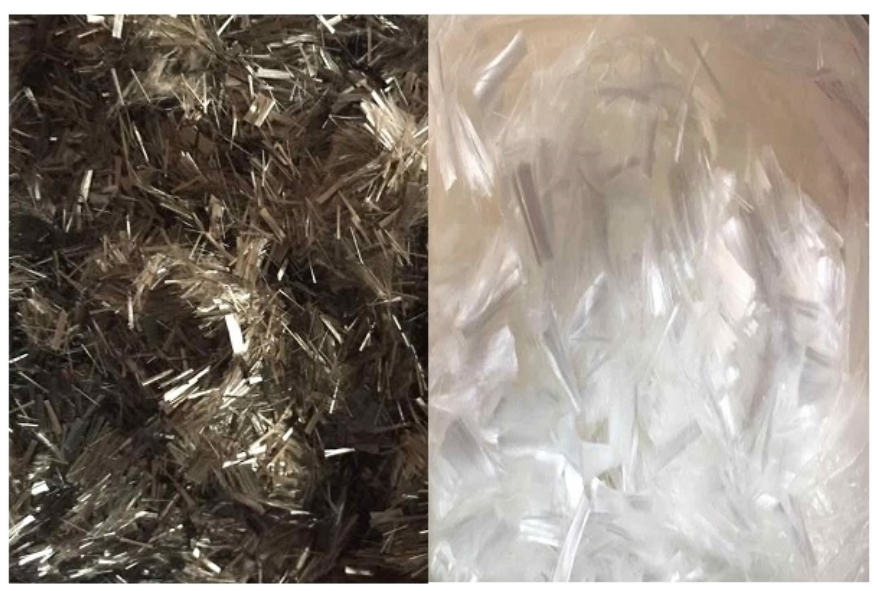

(a) basalt fiber (b) polypropylene fiber

Figure 2. The two kinds of fibers Figure2.

\section{Compressive Strength Test ${ }^{[10,11]}$}

The concrete specimens are submerged in fresh water for 3, 7, 18, and 28 days. Then, compressive strength tests are carried out.

\section{Compressive strength test of specimens with fibers and the tailings particle size range from 0.15-0.3mm}

It is found that the content of iron tailings significantly influences the compressive strength of pavement cement concrete. As shown in Figure 3, throughout the maintenance process, the compressive strength always increases. It is clear that the increase in the compressive strength of pavement cement concrete with iron tailings is faster in the later stages than that in the early stages.

(1) Compared with the standard specimen, the 28-day compressive strength of a specimen with iron tailings and fibers is higher. The growth rate is about 7\%. A possible reason for this may be that the active chemical composition of the iron tailings has fully reacted with the cement.

(2) In Figure 3, it is shown that the compressive strength first increases and then decreases as the content of iron tailings increases with a parabola-like dependence. The peak value is $49.6 \mathrm{MPa}$ for the concrete specimen with $25 \%$ iron tailings. When content of iron tailings continues to increase, the content of sand decreases, and the mixture gradation becomes poor. The particle-size distribution of the mixture is too small; thus, the compressive strength of the specimen is low. The aggregate seriously affected the compressive strength of concrete. Therefore, there is an optimal value for the 
content of iron tailings for pavement cement concrete. So that is to say the concrete with iron tailings and fibers also follows the law of conservation of time.

(3)Compare Figure 3 and Figure 4, the value of compressive strength of cement concrete with the same iron tailings and with different fibers does not change much. That shows the fiber do not afford much effect on compressive strength for cement concrete.
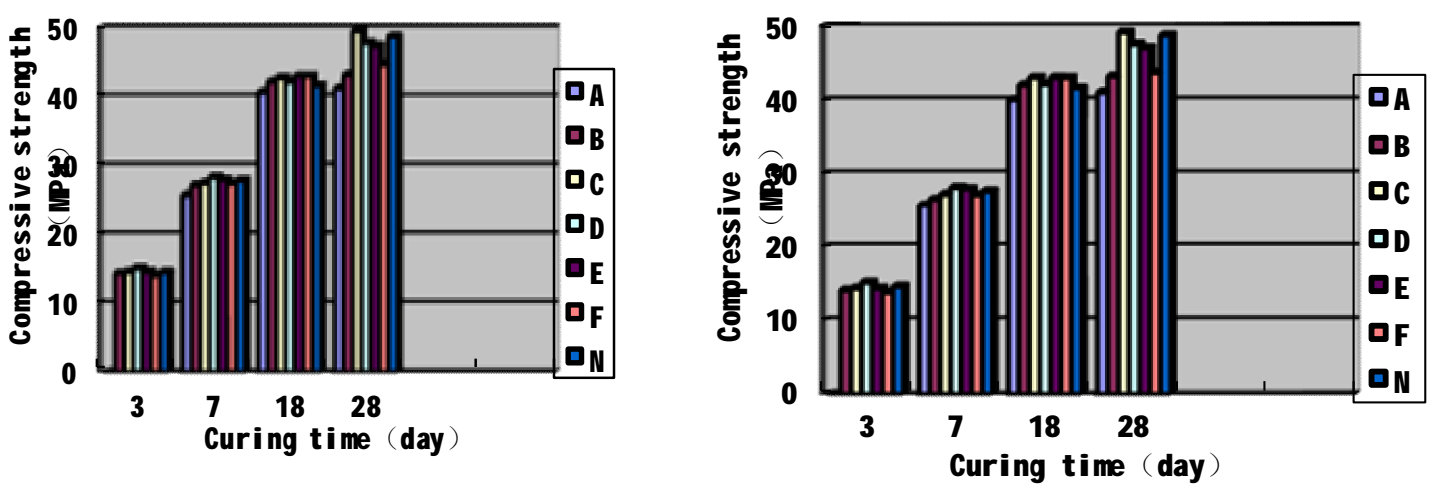

Figure 3. Compressive strength of concrete with iron tailings particles range from $0.15-0.3 \mathrm{~mm}$ and basalt fibers

Figure 4. Compressive strength of concrete with iron tailings particles range from $0.15-0.3 \mathrm{~mm}$ and polypropylene fibers

In Figure 3, a phenomenon is shown, the compressive strenght histogram first increased and then decreased with the increase of the content of iron tailings. It looks like a parabola. The peak value is 49.6Mpa in concrete specimen with $25 \%$ iron tailings.

\section{Compressive strength test of specimens with fibers and the tailings particle size range from} 0.3-0.6mm

Compared with the standard specimen, most of the 28-day compressive strengths of specimens with fibers and iron tailings with particles sizes in the range of $0.3-0.6 \mathrm{~mm}$ are higher. A possible reason for this may be that the active chemical composition of the iron tailings has fully reacted with the cement. The compressive strength curves for A', B', C', D', E', and F' almost all gradually increase and reach a peak compressive strength at 28 days. The highest compressive strength is obtained when the content of iron tailings is $25 \%$ in sand, and it is higher than that of normal concrete. As the content of iron tailings increases, the compressive strength decreases. Although the strength of the iron tailings is lower than that of gravels, the active chemical composition of the iron tailings can fully react with the cement. Overall, the mixture with iron tailings has an advantage in compression.

\section{Compressive strength test of specimens with the same particle size and different content of iron tailings}

Compared with concrete with iron tailings having a particle size in the range of $0.15-0.3 \mathrm{~mm}$, the compressive strength of concrete with the iron tailings having a particle size in the range of $0.3-0.6$ $\mathrm{mm}$ is lower in general. It is concluded that large particles of iron tailings can absorb a larger amount of water during the test. Therefore, the compressive strength is adversely affected.

\section{Flexural Strength Test}

Iron tailings and fibers may have a significant influence on the flexural strength of pavement cement concrete. Thus, flexural strength tests were carried out to assess the extent of this influence.

\section{Flexural strength test of specimens with iron tailings}

In this part a series of tests were done to explore the variation of flexural strength on pavement concrete with two kinds of fibers and with iron tailings. As shown in Fingure 5, iron tailings are influenced flexural strength slightly. The trend in the flexural strength of specimens with iron tailings having a particle size in the range of $0.3-0.6 \mathrm{~mm}$ is similar to that of specimens with iron tailings having a particle size in the range of $0.15-0.3 \mathrm{~mm}$. This may be due to two main reasons. First, the strength of the iron tailings is lower than that of sand. Second, the connections between particles of iron tailings and sand are weaker than that between sand particles because of the roughness of the particle surface. However, the flexural performance of pavement cement concrete with iron tailings is not significantly lower. 


\section{Flexural strength test of specimens with fibers}

The fiber can effectively enhance the flexural and crack resistance of concrete, and compesate for the addition of iron tailings to the concrete bending capacity of the lack of capacity. ${ }^{[12,13]}$ So Fingure 6 shows the change for cement concrete with fibers and with iron tailings. Comparison of basalt fibers and polypropylene fibers can be found that basalt fiber was shorter than polypropylene fiber and had metallic luster. Flexural strength of concrete with iron tailings and with basalt fibers is higer than the flexural strength of concrete with iron tailings and with polypropylene fibers. This rule is applicable to concrete with different iron tailings and different sizes.

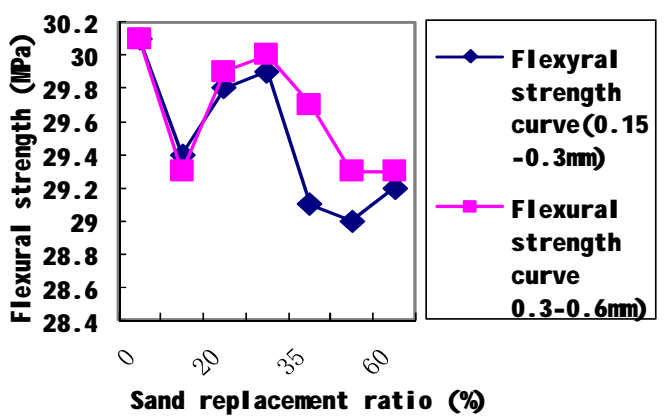

Figure 5. Flexural strength curve of concrete with iron tailings

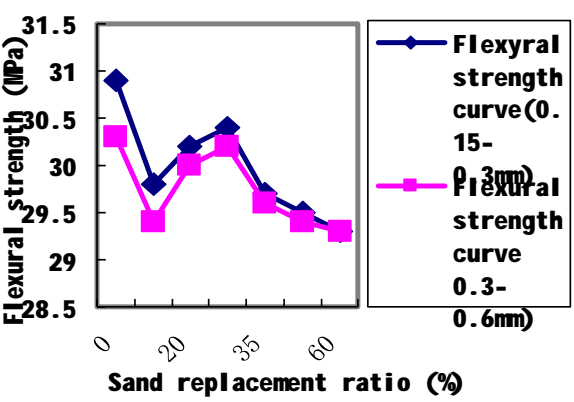

Figure 6. Flexural strength curve of concrete with iron tailings and fibers

\section{Numerical simulation of pavement cement concrete with iron tailings and fibers}

The material composition of pavement cement concrete can largely affect its force characteristics. In particular, when sand is partially substituted with iron tailings, the stress analysis is different. In order to study an actual pavement situation with wheel loads, a numerical simulation analysis is carried out using ANSYS to simulate the force situation.

\section{Modeling}

(1)Modeling principles

In order to reflect the situation in which pavement cement concrete is subjected to wheel loads accurately, the modeling is based on the following assumptions.

a) The density of the pavement is uniform.

b) The wheel load is symmetrical.

c) SI units are used.

(2) Simplification of the model

In the simulation, a SOLID45 element is used to define a three-dimensional model of the pavement cement concrete. There are eight nodes in one element and three degrees of freedom (DOFs) marked X, Y, and Z. The planar size of the concrete model is $7 \times 7 \mathrm{~mm}^{2}$, and the depth of the soil foundation is $7 \mathrm{~m}$.

\section{Parameter definition}

(1)Material definition

*SOIL_CONCRETE in ANSYS is used to depict the inherent characteristics of the pavement cement concrete. From top to bottom, the materials in the pavement structure in this simulation are cement concrete with iron tailings and fibers, cement-stabilized macadam, graded gravel, and the soil foundation. All levels of the road are the same, except for the surface layer in different models.

\section{(2)Control and boundary definitions}

It is necessary to enforce some restrictions on the pavement cement concrete model. The wheel load can affect the pavement and subgrade but not the soil foundation which has a depth of $7 \mathrm{~m}$. Thus, the bottom of the model is fully constrained. The other boundaries of the pavement cement concrete 
model are constrained by normal displacement. Further, the wheel load is located at the center of the pavement cement concrete model, which is simplified as two circular uniform loads. The distance between the centers of the two wheels is $31.95 \mathrm{~cm}$. The radius of the circular uniform load is $10.65 \mathrm{~cm}$. Considering the actual working conditions and simulation method, each wheel load is $0.7 \mathrm{MPa}$.

\section{Results and analysis}

From the simulation results, the displacement in the

Table 5. Simulation results of deflection values for all test plans

$\mathrm{z}$ direction can represent the deflection of the pavement cement concrete. The elements located at the middle of the wheel loads are considered, and the deflection values for all test plans are listed in Table 5.

It is found that as the content and particle size of the iron tailings changes and fiber type changes, the deflection does not significantly change. However, the deflection value of cement concrete with iron tailings and basalt fibers is lower. The content of iron tailings and the kind of fibers are adjusted to achieve an appropriate content range so that the deflection decreases. This content range of iron tailings in the fine aggregate should be $20 \%-35 \%$ in sand. In addition, the particle size of the iron tailings does not have a significant effect on the deflection from the simulation results.

The simulation results are in good agreement with the

\begin{tabular}{|c|c|c|}
\hline $\begin{array}{l}\text { Test plan } \\
\text { code }\end{array}$ & $\begin{array}{c}\text { Deflection value } \\
(0.01 \mathrm{~mm}) \\
\end{array}$ & Fiber type \\
\hline $\mathrm{N}$ & $28.6(28.2)$ & \multirow{13}{*}{$\begin{array}{l}\text { polypropylene } \\
\text { fiber } \\
\text { ( basalt fiber) }\end{array}$} \\
\hline A & $28.5(28.5)$ & \\
\hline B & $28.4(28.3)$ & \\
\hline $\mathrm{C}$ & $28.3(28.0)$ & \\
\hline $\mathrm{D}$ & $28.2(28.0)$ & \\
\hline E & $28.6(28.5)$ & \\
\hline $\mathrm{F}$ & $28.7(28.5)$ & \\
\hline $\mathrm{A}^{\prime}$ & $28.4(28.4)$ & \\
\hline $\mathrm{B}^{\prime}$ & $28.3(27.8)$ & \\
\hline $\mathrm{C}^{\prime}$ & $28.3(28.0)$ & \\
\hline$D^{\prime}$ & $28.3(28.0)$ & \\
\hline $\mathrm{E}^{\prime}$ & $28.5(28.4)$ & \\
\hline $\mathrm{F}^{\prime}$ & $28.6(28.5)$ & \\
\hline
\end{tabular}
physical test results. The compressive resistance of pavement cement concrete with iron tailings significantly affects the actual deflection of pavement. Thus, the simulation results for test scheme $\mathrm{C}$ had the minimum deflection.

\section{Conclusions}

By testing and simulating pavement cement concrete with iron tailings and fibers, the impact of the content and particle size of iron tailings and fiber type on the compressive strength, flexural strength, and deflection was investigated. The major conclusions are as follows:

(1)It is obvious that the basic mechanical properties of pavement cement concrete are impacted by iron tailings and fibers according to both physical experiments and numerical simulation.

(2)From an analysis of the compressive strength and flexural performance of pavement cement concrete, there is an optimal content of iron tailings of $25 \%$.

(3)The particle size of iron tailings does have a significant influence on the performance of pavement cement concrete. Through research and analysis, iron tailings with particle sizes in the range of $0.15-0.3 \mathrm{~mm}$ have better chemical reaction results for pavement cement concrete.

(4) The fiber has played a positive role in improving the bending and cracking resistance of concrete. Basalt fiber can effectively enhance the concrete flexure strength than polypropylene fiber, due to strength and morphology.

(5)The chemical composition of iron tailings in different areas will affect the properties of pavement cement concrete. However, the best content and particle size of iron tailings can be found to replace normal concrete in order to reduce the amount of sand and improve the properties of pavement cement concrete.

\section{References}

[1] Environmental Protection Agency. [Online]. Available: http://www.epa.gov. 
[2] Recycle Materials Resource Center. User guideling for byproducts and secondary use materials in pavement construction. [Online]. Available: http://www.rmrc.unh.

[3] LI Ronghai , WANG Jian , ZHOU Zhihua , LIU Tengi. Research of iron tailings application in the highway engineering, Mineral engineering, vol.5, no.5,pp.52-54, Oct. 2007.

[4] LI LI-han, etl. Road Engineering Materials, MA: China Communications Press, 2015.

[5] Design specification of cement concrete pavement. JTG D40-2003

[6] CAI Ji-wei, ZHANG Shao-bo, HOU Gui-xiang. Eeffects of Ferrous Mill Tailings as Aggreagtes on workability and Strength of Concrete, Journal of Wuhan University of Technology, no.4, pp.104-107, 2009.

[7] Jorge de Brito and Nabajyoti Saikia, Recycled Aggregate in C oncrete, Springer London, 2012, pp:23-80

[8] Andrade LB, Rocha JC, Cheriaf M. Evaluation of concrete incorporating bottom ash as a natural aggregates replacement,Waste Manage, vol. 27, no.9,pp.1190-1199,2007.

[9] WANG Hongxia, YE Jiayuan, ZHANG Wensheng, SHID. Rsearch on high strength concrete made with iron tailing powder, Concrete, no.7,pp.89-91, Junly,2015.

[10] XU Changwei , WANG Bin , WANG Guoguang, MENG Qihan. Influence of composition on the properties of iron tailings aerated concrete,Concrete, no.3,pp.74-77, Junly,2015.

[11] Zhang Xiaoyan, SongQiang., LiHui, FanXiaodan. Eeffect of Iron Tailings Powder on Properties of C40 Concrete, Bulletin of the Chinese Ceramic Society, vol.32, no.12,pp.2559-2563, Oct. 2013. [12] Zhao Bingbing, He Jingjing, Wang Xuezhi. Experiment of Water Permeation Resistance of Concrete with Basalt-polypropylene Hybrid Fiber,Journal of Lanzhou University of Technology, Vol.42, no.1,pp.139-143,Feb. 2016

[13] Jin Shengji, Zhang Jian, Wang Yanling, Zhang Xin, Li Zhongliang. Experimental Study on Anti-splitting Tensile Properties of The Chopped Basalt Fiber Reinforced Concrete, ,Concrete, no.5,pp.66-69,May,2016. 